\title{
Movement System Dysfunction Applied to Youth and Young Adult Throwing Athletes
}

\author{
Ashley E. Disantis, PT, OCS ${ }^{1} \odot{ }^{a}$, RobRoy Martin, PT, PhD, $\operatorname{CSCS}^{2}$ \\ 1 Department of Physical Therapy, Duquesne University, ${ }^{2}$ Department of Physical Therapy, Duquesne University; University of Pittsburgh Medical \\ Center, Center for Sports Medicine \\ Keywords: young athlete, risk factors, screening examination, upper extremity injury, baseball, movement system
}

https://doi.org/10.26603/001c.30022

\section{International Journal of Sports Physical Therapy}

Vol. 17, Issue 1, 2022

\begin{abstract}
Shoulder and elbow injuries in overhead athletes, especially baseball pitchers, have become more common and result in limited participation. Upper extremity injuries in baseball can occur secondary to high velocity repetitive loading at extreme ranges of motion causing microtrauma to the musculoskeletal structures. With the vast number of youth and young adult baseball players in the United States and the increasing number of throwing related injuries, it is crucial that clinicians can perform a movement system evaluation of the throwing motion. An adequate evaluation of the movement system as it relates to the throwing motion can provide insight into abnormal throwing mechanics and provide rationale for selecting appropriate interventions to address identified impairments that may lead to injury. The purpose of this clinical commentary is to present a recommended movement system evaluation that can be utilized during both pre-season and in-season to assess for modifiable injury risk factors in youth and young adult baseball players.
\end{abstract}

\section{Level of Evidence}

5

\section{INTRODUCTION}

Shoulder and elbow injuries in overhead athletes, especially baseball pitchers, have become more common and result in limited participation. ${ }^{1}$ Upper extremity injuries in baseball can occur secondary to high velocity repetitive loading at extreme ranges of motion causing microtrauma to the musculoskeletal structures. ${ }^{2}$ Given the number of youth, high school, and collegiate baseball players in the United States along with the high prevalence of throwing related injuries, assessments to screen for potential risk factors could be valuable in injury prevention.

Approximately 15 million adults and children play organized baseball in the United States each year, with children in eighth grade or lower accounting for $17 \%$ of participants. ${ }^{3}$ A 2014 survey reported that half of individuals attending high school in the United States are involved in competitive sports, with baseball ranking fourth in partici- pation among males. ${ }^{4}$ At the collegiate level, the popularity of baseball has risen from 667 school sponsored teams during the $1988-89$ season to 1,702 school sponsored teams during the 2019-2020 season. ${ }^{5}$ Throwing related injuries have become a concern as $26-51 \%$ of youth pitchers report shoulder or elbow pain at some point during the season. ${ }^{6-8}$ In fact, a 10-year prospective study conducted by Fleisig et al. ${ }^{9}$ reported youth pitchers had a $5 \%$ chance of sustaining a serious throwing injury within a 10-year time frame. Upper extremity injury at the high school and collegiate level is even more common with the incidence of shoulder injuries reported between 1.39-1.72 injuries per 10,000 athlete exposures (AEs). Elbow injuries are less frequent than shoulder injuries at the high school level with 0.86 injuries per 10,000 AEs. However, elbow related throwing injuries may be more severe as athletes usually miss at least one to three weeks of participation compared to shoulder injuries where athletes usually return within one week. ${ }^{10}$ According

\footnotetext{
Corresponding Author: Ashley Disantis, PT, OCS Department of Physical Therapy

Duquesne University Pittsburgh, PA 15282

USA

Email: disantisa@duq.edu

Phone: 412-396-1811
} 
to the National Collegiate Athletic Association (NCAA) Injury Surveillance program during a 10 -year period between the 2004-2005 season and the 2013-2014 season, the rate of shoulder injuries in collegiate baseball players was 4.02 per 10,000 AEs with $7.1 \%$ requiring surgery and $14.5 \%$ unable to return for the season. The rate of injuries at the elbow was 2.44 per 10,000 AEs with $17.5 \%$ requiring surgery and $28.9 \%$ unable to return for the season. ${ }^{11}$ Because of the high incidence and time required to recover from a throwing related upper extremity injuries in youth and young adult athletes, it is important for clinicians to be able to identify those at risk through a screening process. The purpose of this clinical commentary is to present a recommended movement system evaluation that can be utilized during both pre-season and in-season to assess for modifiable injury risk factors in youth and young adult baseball players.

\section{RISK FACTORS}

While pitch count and arm fatigue have been well documented as significant risk factors for throwing injuries in youth athletes, ${ }^{12-14}$ musculoskeletal impairments have also been identified as risk factors for upper extremity injury. Repetitive throwing can lead to musculoskeletal adaptations in the upper and lower extremity that contribute to increased stress on ligamentous and other soft-tissue structures surrounding the elbow and shoulder. Adaptations may include changes in humeral torsion with abnormal shoulder range of motion as well as abnormal hip range of motion. ${ }^{15-20}$ It may be particularly important to screen for upper and lower extremity deficits in the skeletally immature athlete as overhead throwing at a younger age has the potential to change soft tissue and osseous development. ${ }^{21-23}$

There is conflicting evidence regarding the effect of abnormal shoulder range of motion (ROM), and limited evidence for deficits in shoulder strength on upper extremity injury in high school athletes. Shitara et $\mathrm{al}^{24}$ reported a reduction in glenohumeral internal rotation (IR) ROM at 90 degrees of shoulder abduction to be a risk factor for shoulder injury. Shanley et al. ${ }^{25}$ found a passive shoulder IR loss greater than 25 degrees was predictive of arm injury. Conversely, Tyler et al. ${ }^{26}$ found a loss of IR ROM or total shoulder ROM was not associated with shoulder or elbow injury risk. With regard to glenohumeral strength, Tyler et al. ${ }^{26}$ reported supraspinatus weakness was the only strength measure associated with shoulder injury. Similarly, Shitara et al. ${ }^{24}$ identified side-to-side differences in prone external rotation strength as a risk factor for shoulder and elbow injuries. Despite this conflicting evidence, these factors should be assessed, especially in the presence of faulty throwing mechanics observed during a movement system evaluation.

Musculoskeletal impairments of the lower extremity and trunk should not be overlooked as risk factors for upper extremity injury. In fact, the lower extremity is primarily responsible for initiating the pitching motion and it is estimated that $50 \%$ of the kinetic energy during pitching comes from the hip and the core. ${ }^{27}$ Improper force transfer and poor sequencing of the pitching motion from the lower to the upper extremity results in increased load through the arm. ${ }^{28-30}$ Lumbopelvic strength, particularly of the core and gluteus medius, and single leg stability is crucial as pitchers who demonstrate reduced lumbopelvic control have greater time lost from participation. ${ }^{29}$ Furthermore, an excessive lateral trunk lean, defined as greater than 10 degrees away from the pitching arm, has been shown to lead to increased valgus moment at the elbow and internal rotation moment at the shoulder. ${ }^{31}$

With an adequate assessment of movement system dysfunctions during the throwing motion and complementary static and dynamic examination procedures, appropriate interventions may be prescribed to address ROM, strength, and neuromuscular control deficits to facilitate safe participation in baseball.

\section{THROWING MECHANICS}

An understanding of normal throwing mechanics is necessary to be able to assess for movement system dysfunctions during the throwing motion and allow for appropriate interventions youth and young adult athletes. Throwing is a coordinated sequence of movements with the ultimate goal of achieving high ball velocity and accuracy. Sequential motions of acceleration and deceleration begin from the ground up, with each transferring energy until the point of ball release and upper extremity deceleration. ${ }^{32}$ Throwing mechanics may be best defined using the five phases typically used to describe a pitching motion. These defined phases, which have been previously described in the literature, include: wind up, stride/early cocking, late cocking, acceleration, and deceleration. ${ }^{33}$ These phases can also be used to identify the specific movement dysfunctions associated with ROM, strength, and neuromuscular control deficits.

\section{MOVEMENT SYSTEM DYSFUNCTIONS DURING AN ABNORMAL WIND-UP PHASE}

Wind up begins from a static position with the pitcher facing towards the batter and ends when the lead leg reaches max knee height. The final stage of wind up occurs when the pitcher removes the ball from the glove. ${ }^{33}$ Isometric hip abduction strength is crucial as the body balances on the trail leg while the body winds up away from the intended target to develop potential energy before acceleration. The hip abductors work to maintain the center of gravity over the base of support and prevent pelvic tilting. ${ }^{34}$ Faulty mechanics during this phase can negatively affect the movement system secondary to reduced lower extremity strength, mainly in the hip abductors, poor trunk control, poor balance, premature forward motion, posterior center of gravity, and high hand placement with the shoulder in greater than 90 degrees of abduction. ${ }^{33}$

\section{MOVEMENT SYSTEM DYSFUNCTIONS DURING AN ABNORMAL STRIDE/EARLY COCKING PHASE}

The stride/early cocking phase begins with maximum knee height to point of foot contact of the lead leg. During this phase, $50 \%$ of ball velocity comes from appropriate stride mechanics and trunk rotation. ${ }^{33}$ Deviations in stride mechanics, in terms of stride length, foot angle, and stride an- 
gle, can have negative effects on ball velocity and are associated with an increased risk of upper extremity injury. ${ }^{33}$

Optimal stride length should measure between $85-100 \%$ of the pitcher's height. ${ }^{33} \mathrm{~A}$ short stride results in decreased trunk rotation potential and therefore limited force development. ${ }^{35}$ Shortened stride can result from decreased flexibility, specifically lead leg hamstring tightness or stance leg hip flexor or rotator tightness. Decreased strength, eccentrically in the knee and hip extensors of the lead leg as well as concentrically in the internal rotators of the stance leg, can also cause a shortened stride length. ${ }^{35} \mathrm{~A}$ long stride can negatively affect the movement system and result in premature fatigue and increased global physical exertion, which can in turn can lead to increased risk of upper extremity injury. $8,32,36,37$

When the foot contacts the ground, the foot should be slightly internally rotated, which in the case of a right handed pitcher would be toward third base. ${ }^{33}$ An excessively internally rotated foot results in poor energy transfer to the arm and consequently excessive stress through the anterior shoulder, scapular stabilizers, and medial elbow. This can occur due to reduced hip external rotation ROM in the lead leg and reduced hip internal rotation ROM on the stance leg. ${ }^{33}$ An externally rotated foot will also negatively affect the throwing motion and cause the throwing arm to lag behind the body. This altered relationship between the arm and body can lead to increased stress through the anterior shoulder and medial elbow during the late cocking phase to ball release. An externally rotated foot can occur due to a short stride causing the pitcher to rush through the balance point and presents as reduced ball velocity. ${ }^{33}$ Stride angle is defined as the angle between the lead and stance leg and can be effect by general hip flexibility. With a short stride angle, the pitcher may experience abdominal strains as the obliques must compensate for the lack of lower extremity flexibility. ${ }^{33}$

While the upper extremity remains relatively inactive during this phase, the static and dynamic stabilizers of the scapula and glenohumeral joint work to position the humeral head in the glenoid. To achieve proper positioning and avoid tissue overload, the scapula upwardly rotates and retracts to allow for arm abduction. ${ }^{33,38} \mathrm{~A}$ lack of arm abduction can occur secondary to reduced strength and endurance of the scapular stabilizers and lead to improper positioning of the humeral head in the glenoid.

\section{MOVEMENT SYSTEM DYSFUNCTIONS DURING AN ABNORMAL LATE COCKING PHASE}

The late cocking phase begins with the lead foot contacting the ground through maximal external rotation of the throwing shoulder. ${ }^{39}$ The trunk initiates de-rotation back towards the home plate through coupled contraction of the lead side internal oblique and erector spinae and the stance side external oblique muscles. ${ }^{33}$ Along with the trunk muscles, the gluteus medius and gluteus maximus are active to assist with lumbopelvic stability. The glenohumeral muscles along with the scapular stabilizers are active to upwardly rotate the scapula and compress the humeral head into the glenoid. The allows the upper extremity to achieve the extreme externally rotated position of shoulder required dur- ing this phase. ${ }^{33,40-42}$ Abnormal positioning of the humeral head can result in the upper extremity being posterior to the scapular plane with excessive anterior translation of the humeral head at maximal external rotation. In turn, excessive stress is placed through the anterior capsule and results overactivity of the long head of the biceps in attempt to provide stability to the shoulder. ${ }^{43}$

\section{MOVEMENT SYSTEM DYSFUNCTIONS DURING AN ABNORMAL ACCELERATION PHASE}

The acceleration phase is initiated at shoulder maximal external rotation and ends at ball release. The latissimus dorsi generates the greatest force during acceleration and results in increased ball velocity. ${ }^{44}$ Poor trunk control and decreased activity of the scapular stabilizers result in excessive trunk flexion and decreased abduction angle of the humerus, respectively. These lower and upper extremity deviations result in an 'over the top ball release' and side arm throwing. ${ }^{45}$ Throwing with a side arm position places excessive stress through the medial elbow and can result in ulnar collateral ligament (UCL) injury. ${ }^{32,45}$

\section{MOVEMENT SYSTEM DYSFUNCTIONS DURING AN ABNORMAL DECELERATION PHASE}

The final phase of throwing is deceleration, which starts at ball release and ends with the shoulder in maximum internal rotation and 35 degrees of horizontal adduction. ${ }^{46} \mathrm{Ad}-$ equate lead leg hip internal rotation and flexibility of the lower extremity will allow for a balanced position during follow through. Loss of balance during follow through is a consequence of mechanical problems during the stride phase. ${ }^{33}$ Additionally, without adequate eccentric muscle activity of the posterior shoulder, which is responsible for decreasing external rotation and distraction forces, pitchers are susceptible to glenohumeral internal rotation deficit (GIRD). ${ }^{47}$

\section{SCREENING}

Upper extremity injuries occur with biomechanical overload, meaning the throwing force exceeds the strength of ligamentous and soft tissue structures. In order to minimize the risk of biomechanical overload, screening examinations for potential risk factors may be important in preventing upper extremity injuries caused by abnormalities in the movement system during throwing. For all throwing athletes, especially younger players, this risk factor screen should include monitoring of pitch count. While a well-defined battery of tests is currently lacking for youth, high school, and collegiate throwing athletes, the authors propose an evaluation of the movement system during the phases of the throwing motion, as outlined above, along with objective range of motion, strength, and functional tests to assist with screening for potential injury. Recommendations for static and dynamic screening measures to complement the movement system evaluation are presented below. A summary of recommendations regarding movement system dysfunctions and screening examinations and interventions can be found in Table 1 . 
Table 1. Recommended Screening Examinations and Interventions

\begin{tabular}{|c|c|c|c|c|}
\hline $\begin{array}{l}\text { Movement } \\
\text { System } \\
\text { Dysfunction }\end{array}$ & Abnormal Movements & $\begin{array}{c}\text { Related } \\
\text { Impairments }\end{array}$ & Screening Tests & Interventions \\
\hline $\begin{array}{l}\text { Abnormal } \\
\text { Wind-Up }\end{array}$ & $\begin{array}{l}\text { Premature forward motion, } \\
\text { posterior center of gravity, } \\
\text { high hand placement with } \\
\text { shoulder in greater than } 90 \\
\text { degrees of ABD }\end{array}$ & $\begin{array}{l}\text { Poor trunk control, } \\
\text { poor balance at } \\
\text { maximal lead knee } \\
\text { height, lower } \\
\text { extremity strength } \\
\text { deficits }\end{array}$ & $\begin{array}{l}\text { Hip manual muscle } \\
\text { testing; Single leg squat }\end{array}$ & $\begin{array}{l}\text { Plank } \\
\text { progression } \\
\text { Single leg balance } \\
\text { with perturbation } \\
\text { Standing ABD } \\
\text { Step downs }\end{array}$ \\
\hline \multirow[t]{6}{*}{$\begin{array}{l}\text { Abnormal } \\
\text { Stride/Early } \\
\text { Cocking }\end{array}$} & Shortened stride & $\begin{array}{l}\text { Decreased lead leg } \\
\text { hamstring } \\
\text { tightness or stance } \\
\text { leg hip flexor or } \\
\text { rotator tightness }\end{array}$ & $\begin{array}{l}\text { Flexibility testing of the } \\
\text { hamstrings, hip flexors, } \\
\text { and deep rotators }\end{array}$ & $\begin{array}{l}\text { Stretching of the } \\
\text { hamstrings, hip } \\
\text { flexors, and deep } \\
\text { rotators } \\
\text { Explosive side to } \\
\text { side plyometrics }\end{array}$ \\
\hline & Long stride & $\begin{array}{l}\text { Fatigue and } \\
\text { overexertion }\end{array}$ & & \\
\hline & $\begin{array}{l}\text { Excessive internally rotated } \\
\text { foot }\end{array}$ & $\begin{array}{l}\text { Reduced lead hip } \\
\text { ER of motion and/ } \\
\text { or stance hip IR } \\
\text { range of motion }\end{array}$ & $\begin{array}{l}\text { Range of motion testing } \\
\text { of hip ER of lead leg and } \\
\text { hip IR of stance leg }\end{array}$ & $\begin{array}{l}\text { Hip joint } \\
\text { mobilizations }\end{array}$ \\
\hline & Externally rotated foot & $\begin{array}{l}\text { Decreased lead leg } \\
\text { hamstring } \\
\text { tightness or stance } \\
\text { leg hip flexor or } \\
\text { rotator tightness, } \\
\text { decreased balance }\end{array}$ & $\begin{array}{l}\text { Flexibility testing of the } \\
\text { hamstrings, hip flexors, } \\
\text { and deep rotators; single } \\
\text { leg squat }\end{array}$ & $\begin{array}{l}\text { Stretching of the } \\
\text { hamstrings, hip } \\
\text { flexors, and deep } \\
\text { rotators; single } \\
\text { leg balance with } \\
\text { perturbations }\end{array}$ \\
\hline & Short stride angle & $\begin{array}{l}\text { Global decrease in } \\
\text { hip flexibility }\end{array}$ & $\begin{array}{l}\text { Flexibility testing of the } \\
\text { hip flexors, deep rotators, } \\
\text { iliotibial band, and } \\
\text { hamstrings }\end{array}$ & $\begin{array}{l}\text { Stretching of the } \\
\text { hip flexors, deep } \\
\text { rotators, iliotibial } \\
\text { band, and } \\
\text { hamstrings }\end{array}$ \\
\hline & Decreased arm ABD & $\begin{array}{l}\text { Reduced strength } \\
\text { and endurance of } \\
\text { the scapular } \\
\text { stabilizers }\end{array}$ & $\begin{array}{l}\text { Manual muscle testing of } \\
\text { the shoulder and } \\
\text { scapular muscles; } \\
\text { Shoulder Endurance Test }\end{array}$ & $\begin{array}{l}\text { Rotator cuff } \\
\text { strengthening } \\
\text { Proprioceptive } \\
\text { neuromuscular } \\
\text { facilitation } \\
\text { exercises } \\
\text { Closed chain } \\
\text { upper extremity } \\
\text { plyometrics }\end{array}$ \\
\hline \multirow[t]{2}{*}{$\begin{array}{l}\text { Abnormal } \\
\text { Late Cocking }\end{array}$} & $\begin{array}{l}\text { Poor positioning of the } \\
\text { humeral head in the glenoid, } \\
\text { poor upward rotation of the } \\
\text { scapular, upper extremity } \\
\text { positioned posterior to the } \\
\text { scapular plane }\end{array}$ & $\begin{array}{l}\text { Reduced strength } \\
\text { of the } \\
\text { glenohumeral } \\
\text { musculature and } \\
\text { scapular stabilizers }\end{array}$ & $\begin{array}{l}\text { Manual muscle testing of } \\
\text { the shoulder and } \\
\text { scapular muscles; } \\
\text { Shoulder Endurance Test }\end{array}$ & $\begin{array}{l}\text { Rotator cuff } \\
\text { strengthening } \\
\text { Proprioceptive } \\
\text { neuromuscular } \\
\text { facilitation } \\
\text { exercises } \\
\text { Closed chain } \\
\text { upper extremity } \\
\text { plyometrics }\end{array}$ \\
\hline & & $\begin{array}{l}\text { Reduced } \\
\text { lumbopelvic } \\
\text { stability }\end{array}$ & $\begin{array}{l}\text { Manual muscle testing of } \\
\text { hip } A B D \text {, extension, and } \\
\text { ER; Single leg squat }\end{array}$ & $\begin{array}{l}\text { Abdominal and } \\
\text { hip strengthening } \\
\text { exercises } \\
\text { Plank } \\
\text { progression } \\
\text { Single leg squat } \\
\text { Step downs }\end{array}$ \\
\hline $\begin{array}{l}\text { Abnormal } \\
\text { Acceleration }\end{array}$ & Forward trunk posture & Poor trunk control & $\begin{array}{l}\text { Manual muscle testing of } \\
\text { hip } A B D \text {, extension, and } \\
\text { ER; single leg squat }\end{array}$ & $\begin{array}{l}\text { Abdominal and } \\
\text { hip strengthening } \\
\text { exercises } \\
\text { Plank } \\
\text { progression }\end{array}$ \\
\hline
\end{tabular}




\begin{tabular}{|c|c|c|c|c|}
\hline $\begin{array}{l}\text { Movement } \\
\text { System } \\
\text { Dysfunction }\end{array}$ & Abnormal Movements & $\begin{array}{c}\text { Related } \\
\text { Impairments }\end{array}$ & Screening Tests & Interventions \\
\hline & & & & $\begin{array}{l}\text { Single leg squat } \\
\text { Step downs }\end{array}$ \\
\hline & Decreased arm ABD & $\begin{array}{l}\text { Decreased } \\
\text { strength and } \\
\text { endurance of } \\
\text { scapular stabilizers } \\
\text { and glenohumeral } \\
\text { musculature }\end{array}$ & $\begin{array}{l}\text { Manual muscle testing of } \\
\text { the shoulder and } \\
\text { scapular muscles; } \\
\text { Shoulder Endurance Test }\end{array}$ & $\begin{array}{l}\text { Rotator cuff } \\
\text { strengthening } \\
\text { Proprioceptive } \\
\text { neuromuscular } \\
\text { facilitation } \\
\text { exercises } \\
\text { Closed chain } \\
\text { upper extremity } \\
\text { plyometrics }\end{array}$ \\
\hline \multirow[t]{2}{*}{$\begin{array}{c}\text { Abnormal } \\
\text { Deceleration }\end{array}$} & Poor balance & $\begin{array}{l}\text { Decreased lead leg } \\
\text { hip IR, general } \\
\text { decrease in lower } \\
\text { extremity } \\
\text { flexibility }\end{array}$ & $\begin{array}{l}\text { Range of motion } \\
\text { measurement of lead leg } \\
\text { hip IR; flexibility testing } \\
\text { of the hip flexors, deep } \\
\text { rotators, iliotibial band, } \\
\text { and hamstrings }\end{array}$ & $\begin{array}{l}\text { Joint } \\
\text { mobilizations to } \\
\text { improve hip IR } \\
\text { General flexibility } \\
\text { exercises of the } \\
\text { lower extremity } \\
\text { Single leg balance } \\
\text { with } \\
\text { perturbations }\end{array}$ \\
\hline & $\begin{array}{l}\text { Poor deceleration of } \\
\text { glenohumeral IR }\end{array}$ & $\begin{array}{l}\text { Poor eccentric } \\
\text { control of the } \\
\text { shoulder ER }\end{array}$ & $\begin{array}{l}\text { Manual muscle testing of } \\
\text { the shoulder and } \\
\text { scapular muscles; } \\
\text { Shoulder Endurance Test }\end{array}$ & $\begin{array}{l}\text { Rotator cuff } \\
\text { strengthening } \\
\text { Proprioceptive } \\
\text { neuromuscular } \\
\text { facilitation } \\
\text { exercises } \\
\text { Closed chain } \\
\text { upper extremity } \\
\text { plyometrics }\end{array}$ \\
\hline
\end{tabular}

\section{UPPER EXTREMITY STATIC SCREENING}

\section{GLENOHUMERAL RANGE OF MOTION (ROM)}

An assessment of shoulder ROM should be performed, paying special attention to total shoulder ROM and GIRD. Shoulder ROM deficits may affect the movement system by causing abnormalities in the stride/early cocking, late cocking, acceleration, and deceleration throwing phases. An increased risk of upper extremity injury has been shown to occur in professional athletes with an internal rotation deficit between 15 and 25 degrees on the dominant versus nondominant shoulder or a total range of motion deficit greater than five degrees on the dominant versus non-dominant shoulder. ${ }^{48,49}$ These deficits should be considered risk factors regardless of age as they result in extreme torque and force through the shoulder, especially in the setting poor eccentric control of the posterior musculature during the deceleration phase. ${ }^{25,48-50}$ Shoulder IR and ER ROM should be measured in supine with the humerus in 90 degrees of abduction. If these deficits are present along with an observed movement system dysfunction during throwing, a prevention program should focus on regaining ROM within the parameters described above by targeting joint capsule mobility, muscle/tendon extensibility with the goal of minimizing future injury. ${ }^{51}$

\section{GLENOHUMERAL STRENGTH}

Appropriate strength ratios between agonist and antagonist muscles surrounding the shoulder complex, specifically the internal and external rotators, and the scapula are crucial in maintaining dynamic glenohumeral joint stability during overhead activities. ${ }^{52}$ Strength deficits of the muscles around the glenohumeral joint may cause movement system abnormalities in the stride/early cocking, late cocking, acceleration, and deceleration phases of throwing. Strength measurements should be taken as unilateral ratios between IR and ERs, side-to-side comparisons, as well as strength in relation to body weight. Deficits in these strength ratios have been shown to increase the risk of shoulder pain in baseball players. ${ }^{53,54}$ Hand-held dynamometry can be utilized as high concurrent validity has been demonstrated when comparing the measurements with the standard isokinetic measurements. ${ }^{55-57}$ Normative values for these measures have been previously described by Wilk et al. ${ }^{48,58}$ and are as follows: ER/IR ratio $72-76 \%$, ER torque to body weight ratio $18-23 \%$, IR torque to body weight $26-32 \%$, side-to-side comparison of ER and IRs 95-100\% and $110-115 \%$, respectively. In order to monitor for potential injury risk, these strength measures should be performed during pre-season training and repeated throughout the season. With identification of strength deficits along with an observed movement system dysfunction during throwing, exercise can be prescribed in a prophylactic manner with the goal of minimizing future injury.

\section{UPPER EXTREMITY FUNCTIONAL TESTING}

Along with static strength measurements, functional test- 
ing should be utilized. Several upper extremity functional tests have been described in the literature to help clinicians understand how each segment of the upper extremity interacts with one another. Additionally, functional testing provides the clinician with objective measurements regarding limb asymmetries and sport-specific movements that directly related to glenohumeral and scapular strength.

\section{UPPER EXTREMITY CLOSED CHAIN FUNCTIONAL TESTING}

While overhead throwing is an open chain activity, assessment of shoulder girdle performance in the closed chain will provide useful information on the function of the dynamic stabilizers. With deficits in closed chain performance coupled with a movement system dysfunction, closed chain rehabilitation exercises can be utilized to improve joint approximation and co-contraction in order to train the dynamic stabilizers as well as stimulate mechanoreceptors and improve proprioception. ${ }^{59}$ Deficits in functional stability of the shoulder girdle can lead to abnormal stride/ early cocking, late cocking, acceleration, and deceleration phases. The Closed Kinetic Chain Upper Extremity Stability Test (CKCUEST) is a quantitative test to measure function and stability of the elbow, shoulder, and shoulder girdle. To perform this test, the subject begins in a traditional pushup position for males and a modified-push up position for females. While keeping one hand on the ground, the subject touches the ground on their opposite side and the number of touches over a 15-second period is recorded. 59,60 There is evidence that the CKCUEST is valid, reliable, and responsive test with established normative values ${ }^{61-64}$ It has been suggested that the CKCUEST can be utilized as a screening test as athletes who sustained an in-season injury had a significantly lower number of touches at the beginning of the season compared to athletes who did not sustain an injury. ${ }^{65}$

A second closed chain functional test is the Upper Quarter Y-Balance test (YBT-UQ) which assesses the ability to reach with one upper extremity while maintaining stability on the other, taking the individual outside of their comfortable base of support. The YBT-UQ is most related to dynamic tasks involving core stability and upper extremity performance, which includes throwing. ${ }^{66}$ The subject is asked to perform a maximal reach in three different directions, medially, inferolaterally, and superiolaterally. ${ }^{67}$ To score this test, the sum of the three reach directions is divided by the upper extremity limb length and multiplied by 100. Gorman et al. ${ }^{67}$ found the YBT-UQ to be reliable for measuring upper extremity reach distance in a closed chain position in active adults. Unlike the CKCUEST, this test is able to utilize the non-injured upper extremity as "normal" which is beneficial for use with throwers as it allows for identification of side-to-side differences in functional performance. 66

\section{UPPER EXTREMITY OPEN CHAIN FUNCTIONAL TESTING}

Open chain functional tests should also be utilized when assessing throwers as throwing is an open chain activity. An commonly utilized open chain functional test is the seated single-arm-shot-put (SSASP) test, which replicates activ- ities requiring a short burst of maximal pushing activity by the upper extremity. ${ }^{68}$ The subject sits with their back against a wall with their knees bent to 90 degrees. The subject is then asked to push the ball, not throw it, as far as possible while keeping their head and scapula against the wall and the contralateral arm in their lap. A $2.72 \mathrm{~kg}$ (6 pound) medicine ball is utilized during this test. Two practice attempts are given, one at $75 \%$ effort and the other at $100 \%$ effort, followed by three maximal-effort attempts. The distance from the wall to the spot where the ball contacts the floor is measured and the results are averaged together. A study by Chmielewski et al. ${ }^{69}$ examined different normalization methods and recommend allometric scaling with the exponent $0.35\left(\mathrm{~cm} / \mathrm{kg}^{0.35}\right)$ be utilized to remove the influence of body mass on the results of this test. Additionally, the authors note that better performance should be expected on the dominant limb than the non-dominant limb and asymmetry up to $10 \%$ may be acceptable. ${ }^{69}$ Previous research has shown this test has excellent test-retest reliability and reflects upper extremity strength in healthy individuals.

More recently, the Shoulder Endurance Test (SET) has been developed as a measure muscle endurance capacity and mimic overhead sporting activities. Assessment of muscular endurance is important in pitchers as fatigue is a common risk factor for shoulder injury and athletes with a history of shoulder pain demonstrate more fatigue than their healthy counterparts. ${ }^{70}$ To perform this test, the subject stands barefoot with their back against a wall and the non-testing hand placed on their spine near the $4-5^{\text {th }}$ lumbar vertebrae. The foot opposite of the testing arm is place forward in a staggered stance position. The testing arm is placed in 90 degrees of forward flexion holding a 1-m long TheraBand fixed at shoulder height. The subject is then asked to pull the TheraBand to a $90-90$ position of abduction and external rotation at a cadence given by a metronome. The subject performs as many repetitions as possible until fatigue. Fatigue is defined as the inability to keep the pace of the metronome, inability to reach the ending position after two verbal cues, or a verbal report of the inability to continue. The verbal report of fatigue is standardized by using a Borg rating of perceived exertion sale where fatigue was reported at a level exceeding 14 out of 20. ${ }^{71}$ Test-retest reliability has been demonstrated to be high (ICC=0.93) for the dominant upper extremity in overhead athletes. Relative reliability in both sedentary individuals and overhead athletes has been shown to be high to very high and the test is able to assess overhead functionality as well as side-to-side differences in muscle endurance. While this test may be utilized to assess shoulder endurance, the SET demonstrates a weak correlation between isometric shoulder rotational strength and therefore should be utilized in conjunction with strength testing as outlined above. ${ }^{71}$

\section{LOWER EXTREMITY SCREENING}

\section{HIP RANGE OF MOTION}

Normal hip rotational ROM is crucial to allow for appropriate energy transfer from the lower extremity to the upper 
extremity during pitching. Hip range of motion deficits may affect the movement system by causing abnormalities in the stride/early cocking and deceleration throwing phases. Reduced lead hip rotational ROM results in decreased stride length and reduced force production whereas increase in lead rotational hip ROM results in a lag between early trunk rotation and the pitching shoulder. In both of these scenarios, the pitcher compensates with increased shoulder ER putting both the glenohumeral and elbow joints at risk for injury. ${ }^{33,72,73}$ Saito et al. ${ }^{73}$ reported lead and trail leg limitations of hip flexion ROM and internal rotation at 90 degrees of hip flexion were risk factors for elbow injuries adolescent baseball players. In elite young baseball players, Sekiguchi et $\mathrm{al}^{74}$ found a decrease in hip IR ROM on the stride leg was significantly associated with elbow or shoulder pain (38.5 degrees vs. 43.7 degrees, $p=.002$ ). In high school baseball players, Hamano et al. ${ }^{75}$ reported a hip ER ROM deficit on the dominant side (lag leg) was significantly decreased in injured versus non-injured players (injured vs non-injured: $15.8+3.6$ vs $15.4+3.3, p=0.04$ ). Assessing specifically hip flexion, internal rotation, and external rotation, should be of particular interest during pre-season screening examinations of youth and young adult baseball players because of the known importance of these motions for normal mechanics. Since appropriate hip ROM values have not been well established, these static measures, obtained through traditional goniometry, should be correlated to findings of the throwing movement system assessment.

\section{LUMBOPELVIC STRENGTH}

Special attention should be given to pre-season lumbopelvic strength as weakness of the hip abductors leads to a poor energy transfer in the kinetic chain and consequently increased stress through the upper extremity. ${ }^{76}$ Lumbopelvic strength deficits may affect the movement system by causing abnormalities during the wind-up, late cocking, and acceleration throwing phases. The hip abductors, specifically the gluteus medius and gluteus maximus, are active throughout the throwing motion. On the lead leg, they work to decelerate the knee, provide a stable base, and absorb force from deceleration and follow through phases. ${ }^{77}$ On the trail leg, the abductors stabilize the pelvis and provide balance from wind-up to early cocking. ${ }^{78}$ Weakness through the hip abductors may result in knee valgus, a trunk lean, pelvic drop, or a reduction in balance resulting in upper extremity compensations. ${ }^{79}$ With identification of static strength deficits, obtained through standard manual muscle testing, along with an observed movement system dysfunction during throwing, lumbopelvic strengthening exercises can be prescribed in a prophylactic manner with the goal of minimizing future injury.

\section{LOWER EXTREMITY FUNCTIONAL TESTING}

The single leg squat test has been shown to be a valid in assessing dynamic lower extremity control and hip muscle function. ${ }^{79,80}$ A study by Wasserberger et al. ${ }^{81}$ found the single leg squat to be a useful assessment tool in adolescent athletes, as single leg squat mechanics were related to stride knee mechanics. Minimizing knee valgus during the

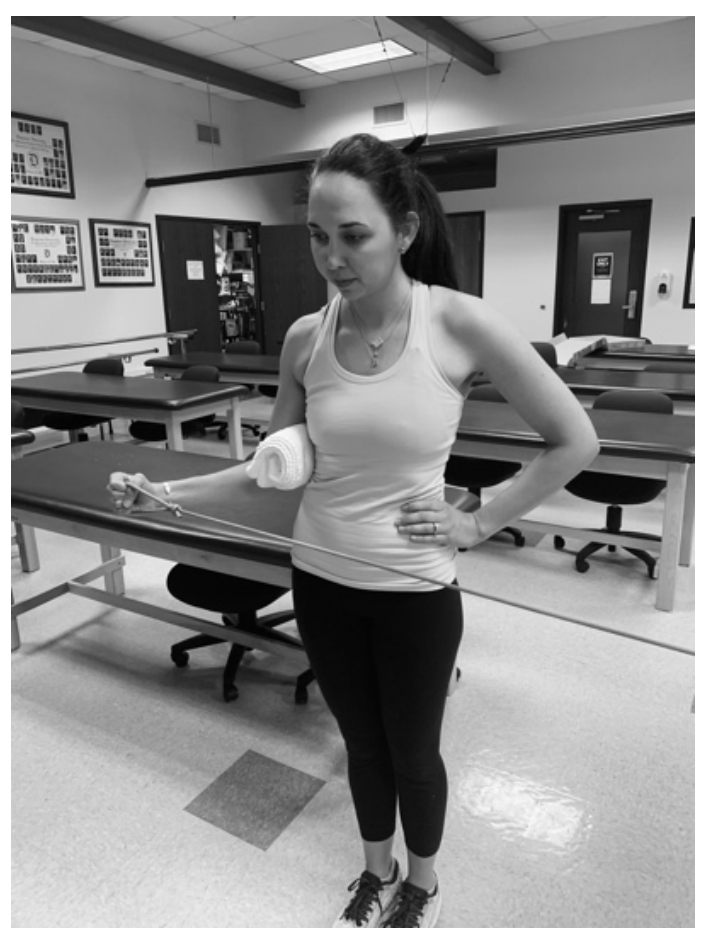

Figure 1a. Standing Shoulder External Rotation Strengthening

throwing motion, especially of the stride knee, may result in better transfer up the kinetic chain and a reduction in both upper and lower extremity injuries. When assessing a single-leg squat, the clinician should pay careful attention to the position of the trunk, pelvis, and knee. With identification of poor mechanics during the single leg squat coupled with an observed movement system dysfunction during throwing, exercises to improve strength and functional performance of the lumbopelvic musculature can be prescribed.

\section{DISCUSSION}

The demands of throwing on the upper extremity lead to frequent injuries of both the shoulder and elbow in youth and young adult baseball players. Given the time lost from participation due to injury, pre-season screening examinations should be performed to assess for risk factors that may result in upper extremity injury. Additionally, an assessment of the throwing motion should be performed to screen for any movement system dysfunctions that may occur during each of the five phases. When possible, objective findings during the screening examinations should be compared to a throwing assessment to facilitate optimal performance.

Upper extremity screening should include as assessment of glenohumeral range of motion and strength. When an IR ROM deficit is identified, posterior glides of the glenohumeral joint and posterior capsule stretching are recommended. If deficits in ER strength are observed, infraspinatus and teres minor strengthening should be prescribed with special attention to strengthening exercises that mimic the overhead throwing motion (Figure 1). 
At least one functional assessment of the upper extremity should also be utilized during screening for upper extremity kinetic chain performance. Poor performance on any of the upper extremity functional testing should be compared to findings of shoulder strength and ROM screens as well as the throwing assessment to ensure appropriate prescription of exercise. For example, decreased shoulder ER strength and poor performance on the SET may result in an abnormal late cocking movement system dysfunction. In this case, scapular endurance exercises as well as shoulder ER strengthening in abduction may be prescribed (Figure 2).

The lower extremity should also be screened for hip range of motion deficits as well as deficits in lumbopelvic strength. Hip flexion, internal rotation, and external rotation ROM deficits can be addressed with inferior, posterior, and anterior hip joint mobilizations, respectively (Figure 3). Appropriate muscle stretching should be prescribed to compliment hip joint mobilizations with the goal regaining appropriate ROM and improving of any movement system dysfunctions identified that relate to limited hip ROM.

Manual muscle testing of the hip abductors, hip extensors, hip external rotators, and abdominals can be used to screen for strength deficits of the lumbopelvic stabilizers. In order to assess functional performance of the lower extremity kinetic chain and core, a single leg squat test is recommended. ${ }^{82}$ Deficits in hip muscle strength and lower extremity neuromuscular control can be addressed with exercises that emphasis movements that closely resemble the phases of the throwing motion. For example, weakness of the hip abductors and poor control during single leg squat may result in an observed abnormal wind-up movement system dysfunction. In this case, perturbations during single leg balance drills would challenge both balance and hip abductor strengthening in a position that mimics the windup phase (Figure 4).

\section{CONCLUSION}

Shoulder and elbow injuries in overhead athletes, especially throwers, are increasingly common and result in lost participation time. ${ }^{1}$ Throwing requires the shoulder, elbow, trunk, and lower extremities to withstand large forces at extreme ranges of motion. ${ }^{41,83,84}$ An adequate evaluation of the movement system as it relates to the throwing motion can provide insight into abnormal throwing mechanics and provide rationale for selecting appropriate interventions to address identified impairments that may lead to injury. This review presents a recommended movement system evaluation that can be utilized during both pre-season and in-season to assess for modifiable injury risk factors in youth and young adult baseball players.

Screening procedures can provide rationale for selecting potential interventions to address the identified impairments that are potential risk factors for throwing injuries.
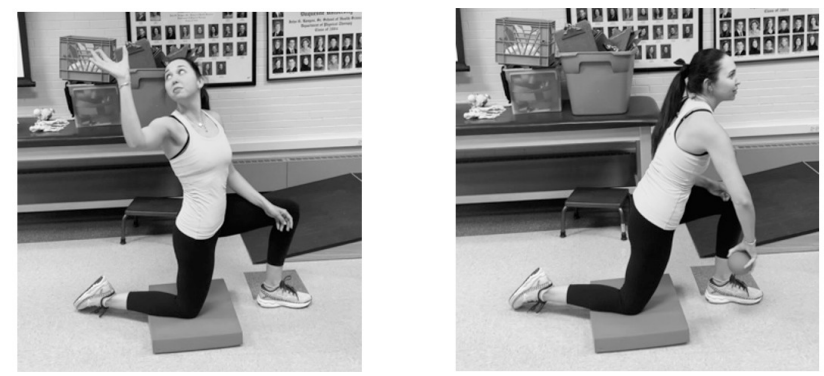

\section{Figure 1b. Eccentric Ball Toss}

Left: Starting position; Right: Ending Position
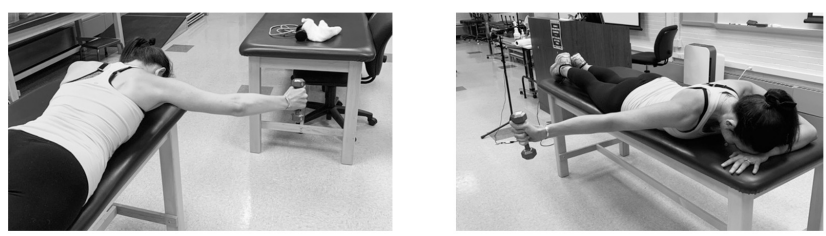

Figure 2. Scapular Strengthening Exercises

Left: Prone Y to address lower trapezius; Right-Prone T to address middle trapezius
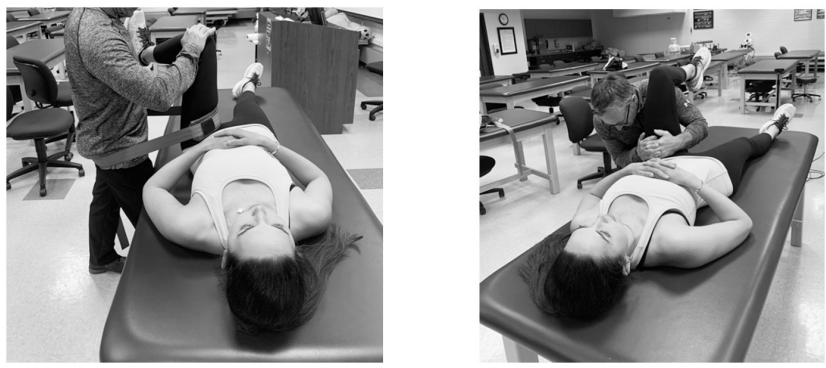

Figure 3. Hip Joint Mobilizations

Left: distraction to address internal rotation ROM deficit; Right: inferior glide to address flexion ROM deficit 

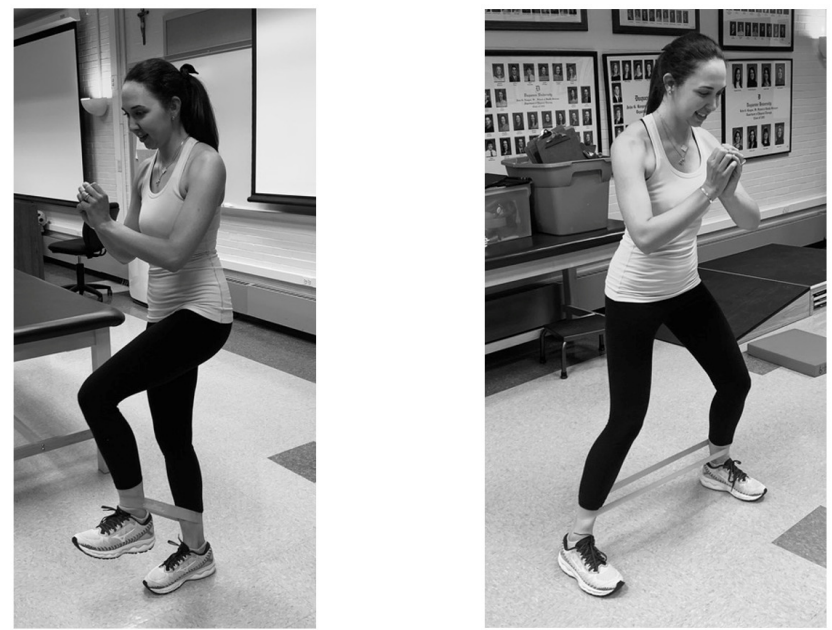

Figure 4a. Hip abductor strengthening mimicking wide up (left) and stride (right)

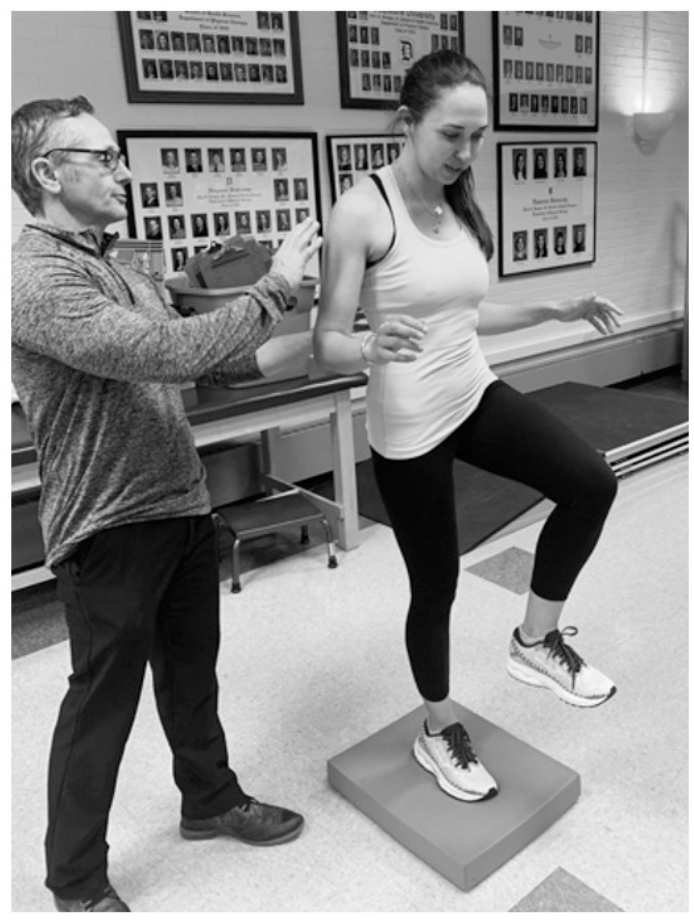

Figure 4b. Single leg balance with perturbations

This is an open-access article distributed under the terms of the Creative Commons Attribution 4.0 International License (CCBY-NC-4.0). View this license's legal deed at https://creativecommons.org/licenses/by-nc/4.0 and legal code at https://creativecommons.org/licenses/by-nc/4.0/legalcode for more information. 


\section{REFERENCES}

1. Conte S, Requa RK, Garrick JG. Disability days in major league baseball. Am J Sports Med. 2001;29(4):431-436. doi:10.1177/03635465010290040 $\underline{801}$

2. Chalmers PN, Wimmer MA, Verma NN, et al. The Relationship Between Pitching Mechanics and Injury: A Review of Current Concepts. Sports Health. 2017;9(3):216-221. doi:10.1177/1941738116686545

3. Register-Mihalik J, Oyama S, Marshall SW, Mueller F. Pitching practices and self-reported injuries among youth baseball pitchers: a descriptive study. Athl Training Sports Health Care. 2012;4:11-20.

4. National Federation of State High School Associations. 2014-2015 high school athletics participation survey results. Accessed March 24, 2021. http://www.nfhs.org/ParticipationStatics/PDF/2014-1 5 Participation_Survey_Results.pdf

5. Irick E. NCAA Student-Athlete Participation Rates Report. National collegiate athletic association (NCAA); 2017.

6. Albright JA, Jokl P, Shaw R, Albright JP. Clinical study of baseball pitchers: correlation of injury to the throwing arm with method of delivery. Am J Sports Med. 1978;6(1):15-21. doi:10.1177/036354657800600 $\underline{104}$

7. Lyman S, Fleisig GS, Waterbor JW, et al. Longitudinal study of elbow and shoulder pain in youth baseball pitchers. Med Sci Sports Exerc. 2001;33(11):1803-1810. doi:10.1097/00005768-20011 1000-00002

8. Lyman S, Fleisig GS, Andrews JR, Osinski ED. Effect of pitch type, pitch count, and pitching mechanics on risk of elbow and shoulder pain in youth baseball pitchers. Am J Sports Med. 2002;30(4):463-468. doi:1 $\underline{0.1177 / 03635465020300040201}$

9. Fleisig GS, Andrews JR, Cutter GR, et al. Risk of serious injury for young baseball pitchers: a 10-year prospective study. Am J Sports Med.

2011;39(2):253-257. doi:10.1177/0363546510384224

10. Saper MG, Pierpoint LA, Liu W, Comstock RD, Polousky JD, Andrews JR. Epidemiology of Shoulder and Elbow Injuries Among United States High School Baseball Players: School Years 2005-2006 Through 2014-2015. Am J Sports Med. 2018;46(1):37-43. doi:1 $\underline{0.1177 / 0363546517734172}$
11. Cross KM, McMurray M, Hertel J, et al. Shoulder and Elbow Injury Rates and Characteristics among Collegiate Baseball Student-Athletes. Int J Sports Phys Ther. 2020;15(5):792-803. doi:10.26603/ijspt2020079 $\underline{2}$

12. Wojtys EM. Play Ball! Sports Health. 2018;10(2):108-109. doi:10.1177/1941738118756280

13. Norton R, Honstad C, Joshi R, Silvis M, Chinchilli V, Dhawan A. Risk Factors for Elbow and Shoulder Injuries in Adolescent Baseball Players: A Systematic Review. Am J Sports Med. 2019;47(4):982-990. doi:1 $\underline{0.1177 / 0363546518760573}$

14. Salamh P, Jones E, Bashore M, Liu X, Hegedus EJ. Injuries and associated risk factors of the shoulder and elbow among adolescent baseball pitchers: A systematic review and meta-analysis. Phys Ther Sport. 2020;43:108-119. doi:10.1016/j.ptsp.2020.02.013

15. Astolfi MM, Struminger AH, Royer TD, Kaminski TW, Swanik CB. Adaptations of the Shoulder to Overhead Throwing in Youth Athletes. J Athl Train. 2015;50(7):726-732. doi:10.4085/1062-6040-50.1.14

16. Greenberg EM, Lawrence JT, FernandezFernandez A, McClure P. Humeral Retrotorsion and Glenohumeral Motion in Youth Baseball Players Compared With Age-Matched Nonthrowing Athletes. Am J Sports Med. 2017;45(2):454-461. doi:10.1177/036 $\underline{3546516676075}$

17. Hibberd EE, Oyama S, Tatman J, Myers JB. Dominant-limb range-of-motion and humeralretrotorsion adaptation in collegiate baseball and softball position players. $J$ Athl Train.

2014;49(4):507-513. doi:10.4085/1062-6050-49.3.23

18. Meyer CJ, Garrison JC, Conway JE. Baseball Players With an Ulnar Collateral Ligament Tear Display Increased Nondominant Arm Humeral Torsion Compared With Healthy Baseball Players. Am J Sports Med. 2017;45(1):144-149. doi:10.1177/036354 $\underline{6516664718}$

19. Whiteley R, Ginn K, Nicholson L, Adams R. Indirect ultrasound measurement of humeral torsion in adolescent baseball players and non-athletic adults: reliability and significance. J Sci Med Sport. 2006;9(4):310-318. doi:10.1016/j.jsams.2006.05.012

20. Sciascia A, Kibler WB. The pediatric overhead athlete: what is the real problem? Clin J Sport Med. 2006;16(6):471-477. doi:10.1097/01.jsm.000025118 2.44206.3b 
21. Hibberd EE, Oyama S, Myers JB. Increase in humeral retrotorsion accounts for age-related increase in glenohumeral internal rotation deficit in youth and adolescent baseball players. Am J Sports Med. 2014;42(4):851-858. doi:10.1177/036354651351 $\underline{9325}$

22. Myers JB, Oyama S, Goerger BM, Rucinski TJ, Blackburn JT, Creighton RA. Influence of humeral torsion on interpretation of posterior shoulder tightness measures in overhead athletes. Clin J Sport Med. 2009;19(5):366-371. doi:10.1097/ISM.0b013e318 $\underline{1 \mathrm{~b} 544 \mathrm{f} 6}$

23. Ray TR. Youth baseball injuries: recognition, treatment, and prevention. Curr Sports Med Rep. 2010;9(5):294-298. doi:10.1249/JSR.0b013e3181f2740 $\underline{3}$

24. Shitara H, Kobayashi T, Yamamoto A, et al. Prospective multifactorial analysis of preseason risk factors for shoulder and elbow injuries in high school baseball pitchers. Knee Surg Sports Traumatol Arthrosc. 2017;25(10):3303-3310. doi:10.1007/s0016 7-015-3731-4

25. Shanley E, Rauh MJ, Michener LA, Ellenbecker TS, Garrison JC, Thigpen CA. Shoulder range of motion measures as risk factors for shoulder and elbow injuries in high school softball and baseball players. Am J Sports Med. 2011;39(9):1997-2006. doi:10.1177/0 $\underline{363546511408876}$

26. Tyler TF, Mullaney MJ, Mirabella MR, Nicholas SJ, McHugh MP. Risk Factors for Shoulder and Elbow Injuries in High School Baseball Pitchers: The Role of Preseason Strength and Range of Motion. Am J Sports Med. 2014;42(8):1993-1999. doi:10.1177/0363546514 $\underline{535070}$

27. McMullen J, Uhl TL. A kinetic chain approach for shoulder rehabilitation. J Athl Train. 2000;35(3):329-337.

28. Putnam CA. Sequential motions of body segments in striking and throwing skills: descriptions and explanations. J Biomech. 1993;26 Suppl 1:125-135. do $\mathrm{i}: 10.1016 / 0021-9290(93) 90084-\mathrm{r}$

29. Chaudhari AM, McKenzie CS, Pan X, Onate JA. Lumbopelvic control and days missed because of injury in professional baseball pitchers. Am J Sports Med. 2014;42(11):2734-2740. doi:10.1177/036354651 $\underline{4545861}$

30. Laudner KG, Wong R, Meister K. The influence of lumbopelvic control on shoulder and elbow kinetics in elite baseball pitchers. J Shoulder Elbow Surg. 2019;28(2):330-334. doi:10.1016/i.jse.2018.07.015
31. Oyama S, Yu B, Blackburn JT, Padua DA, Li L, Myers JB. Effect of excessive contralateral trunk tilt on pitching biomechanics and performance in high school baseball pitchers. Am J Sports Med. 2013;41(10):2430-2438. doi:10.1177/03635465134965 $\underline{47}$

32. Fleisig GS, Andrews JR, Dillman CJ, Escamilla RF. Kinetics of baseball pitching with implications about injury mechanisms. Am J Sports Med. 1995;23(2):233-239. doi:10.1177/03635465950230021 $\underline{8}$

33. Calabrese GJ. Pitching mechanics, revisited. Int J Sports Phys Ther. 2013;8(5):652-660.

34. Klingenstein GG, Martin R, Kivlan B, Kelly BT. Hip injuries in the overhead athlete. Clin Orthop Relat Res. 2012;470(6):1579-1585. doi:10.1007/s11999-012-224 5-3

35. Cain EL Jr, Andrews JR, Dugas JR, et al. Outcome of ulnar collateral ligament reconstruction of the elbow in 1281 athletes: Results in 743 athletes with minimum 2-year follow-up. Am J Sports Med. 2010;38(12):2426-2434. doi:10.1177/03635465103781 $\underline{00}$

36. Crotin RL, Kozlowski K, Horvath P, Ramsey DK. Altered stride length in response to increasing exertion among baseball pitchers. Med Sci Sports Exerc. 2014;46(3):565-571. doi:10.1249/MSS.0b013e3 $\underline{182 \mathrm{a} 79 \mathrm{~cd} 9}$

37. Yang J, Mann BJ, Guettler JH, et al. Risk-Prone Pitching Activities and Injuries in Youth Baseball: Findings From a National Sample. Am J Sports Med. 2014;42(6):1456-1463. doi:10.1177/036354651452469 9

38. Mihata T, Jun BJ, Bui CN, et al. Effect of scapular orientation on shoulder internal impingement in a cadaveric model of the cocking phase of throwing. $J$ Bone Joint Surg Am. 2012;94(17):1576-1583. doi:10.21 $\underline{\text { 06/JBJS.J.01972 }}$

39. Pappas AM, Zawacki RM, Sullivan TJ. Biomechanics of baseball pitching. A preliminary report. Am J Sports Med. 1985;13(4):216-222. doi:10.1 $177 / 036354658501300402$

40. De Wilde L, Plasschaert F, Berghs B, Van Hoecke M, Verstraete K, Verdonk R. Quantified measurement of subacromial impingement. J Shoulder Elbow Surg. 2003;12(4):346-349. doi:10.1016/s1058-2746(03)0003 $\underline{8-7}$ 
41. Fleisig GS, Barrentine SW, Escamilla RF, Andrews JR. Biomechanics of overhand throwing with implications for injuries. Sports Med. 1996;21(6):421-437. doi:10.2165/00007256-19962106 0-00004

42. Manske R, Wilk KE, Davies G, Ellenbecker T, Reinold M. Glenohumeral motion deficits: friend or foe? Int J Sports Phys Ther. 2013;8(5):537-553.

43. Kim SH, Ha KI, Kim HS, Kim SW.

Electromyographic activity of the biceps brachii muscle in shoulders with anterior instability. Arthroscopy. 2001;17(8):864-868. doi:10.1016/s0749-8 063(01)90011-8

44. Bassett RW, Browne AO, Morrey BF, An KN. Glenohumeral muscle force and moment mechanics in a position of shoulder instability. J Biomech. 1990;23(5):405-415. doi:10.1016/0021-9290(90)9029 5-e

45. Dillman CJ, Fleisig GS, Andrews JR. Biomechanics of pitching with emphasis upon shoulder kinematics. J Orthop Sports Phys Ther. 1993;18(2):402-408. doi:1 0.2519/jospt.1993.18.2.402

46. Meister K. Injuries to the shoulder in the throwing athlete. Part one: Biomechanics/pathophysiology/ classification of injury. Am J Sports Med. 2000;28(2):265-275. doi:10.1177/03635465000280022 $\underline{301}$

47. Digiovine NM, Jobe FW, Pink M, Perry J. An electromyographic analysis of the upper extremity in pitching. J Shoulder Elbow Surg. 1992;1(1):15-25. doi:1 0.1016/S1058-2746(09)80011-6

48. Wilk KE, Macrina LC, Fleisig GS, et al. Deficits in Glenohumeral Passive Range of Motion Increase Risk of Shoulder Injury in Professional Baseball Pitchers: A Prospective Study. Am J Sports Med. 2015;43(10):2379-2385. doi:10.1177/03635465155943 $\underline{80}$

49. Wilk KE, Macrina LC, Fleisig GS, et al. Correlation of glenohumeral internal rotation deficit and total rotational motion to shoulder injuries in professional baseball pitchers. Am J Sports Med. 2011;39(2):329-335. doi:10.1177/0363546510384223

50. Ostrander R, Escamilla RF, Hess R, Witte K, Wilcox L, Andrews JR. Glenohumeral rotation deficits in high school, college, and professional baseball pitchers with and without a medial ulnar collateral ligament injury. J Shoulder Elbow Surg. 2019;28(3):423-429. doi:10.1016/j.jse.2018.11.038
51. Hellem A, Shirley M, Schilaty N, Dahm D. Review of Shoulder Range of Motion in the Throwing Athlete: Distinguishing Normal Adaptations from Pathologic Deficits. Curr Rev Musculoskelet Med. Published online 2019:346-355. doi:10.1007/s12178-019-09563-5

52. Yildiz Y, Aydin T, Sekir U, Kiralp MZ, Hazneci B, Kalyon TA. Shoulder terminal range eccentric antagonist/concentric agonist strength ratios in overhead athletes. Scand J Med Sci Sports. 2006;16(3):174-180. doi:10.1111/j.1600-0838.2005.00 $\underline{471 . x}$

53. Byram IR, Bushnell BD, Dugger K, Charron K, Harrell FE Jr, Noonan TJ. Preseason shoulder strength measurements in professional baseball pitchers: identifying players at risk for injury. Am J Sports Med. 2010;38(7):1375-1382. doi:10.1177/036354650936040 $\underline{4}$

54. Clarsen B, Bahr R, Andersson SH, Munk R, Myklebust $\mathrm{G}$. Reduced glenohumeral rotation, external rotation weakness and scapular dyskinesis are risk factors for shoulder injuries among elite male handball players: a prospective cohort study. $\mathrm{Br} \mathrm{J}$ Sports Med. 2014;48(17):1327-1333. doi:10.1136/bjsp orts-2014-093702

55. Cadogan A, Laslett M, Hing W, McNair P, Williams M. Reliability of a new hand-held dynamometer in measuring shoulder range of motion and strength. Man Ther. 2011;16(1):97-101. doi:10.1016/i.math.201 $\underline{0.05 .005}$

56. Hebert LJ, Maltais DB, Lepage C, Saulnier J, Crete $\mathrm{M}$, Perron $\mathrm{M}$. Isometric muscle strength in youth assessed by hand-held dynamometry: a feasibility, reliability, and validity study. Pediatr Phys Ther. 2011;23(3):289-299. doi:10.1097/PEP.0b013e318227cc ff

57. Johansson FR, Skillgate E, Lapauw ML, et al. Measuring Eccentric Strength of the Shoulder External Rotators Using a Handheld Dynamometer: Reliability and Validity. J Athl Train. 2015;50(7):719-725. doi:10.4085/1062-6050-49.3.72

58. Wilk KE, Andrews JR, Arrigo CA, Keirns MA, Erber DJ. The strength characteristics of internal and external rotator muscles in professional baseball pitchers. Am J Sports Med. 1993;21(1):61-66. doi:10.1 177/036354659302100111

59. Goldbeck T, Davies G. Test-retest reliability of the closed kinetic chain upper extremity stability test. Journal of Sports Rehabilitation. 2000;9:35-45.

60. Goldbeck T, Davies G. Test-retest reliability of the closed kinetic chain upper extremity stability test: A clinical field test. Phys Ther. 1999;79. 
61. Roush JR, Kitamura J, Waits MC. Reference Values for the Closed Kinetic Chain Upper Extremity Stability Test (CKCUEST) for Collegiate Baseball Players. N Am J Sports Phys Ther. 2007;2(3):159-163.

62. de Oliveira VM, Pitangui AC, Nascimento VY, da Silva HA, Dos Passos MH, de Araujo RC. Test-Retest Reliability of the Closed Kinetic Chain Upper Extremity Stability Test (Ckcuest) in Adolescents: Reliability of Ckcuest in Adolescents. Int J Sports Phys Ther. 2017;12(1):125-132.

63. Taylor JB, Wright AA, Smoliga JM, DePew JT, Hegedus EJ. Upper-Extremity Physical-Performance Tests in College Athletes. J Sport Rehabil. 2016;25(2):146-154. https://pubmed.ncbi.nlm.nih.go $\mathrm{v} / 25611827 /$

64. Tucci HT, Martins J, Sposito Gde C, Camarini PM, de Oliveira AS. Closed Kinetic Chain Upper Extremity Stability test (CKCUES test): a reliability study in persons with and without shoulder impingement syndrome. BMC Musculoskelet Disord. 2014;15:1. do i:10.1186/1471-2474-15-1

65. Pontillo M, Spinelli BA, Sennett BJ. Prediction of in-season shoulder injury from preseason testing in division I collegiate football players. Sports Health. 2014;6(6):497-503. doi:10.1177/1941738114523239

66. Westrick RB, Miller JM, Carow SD, Gerber JP. Exploration of the y-balance test for assessment of upper quarter closed kinetic chain performance. Int $J$ Sports Phys Ther. 2012;7(2):139-147.

67. Gorman PP, Butler RJ, Plisky PJ, Kiesel KB. Upper Quarter Y Balance Test: reliability and performance comparison between genders in active adults. $J$ Strength Cond Res. 2012;26(11):3043-3048. doi:10.151 9/JSC.0b013e3182472fdb

68. Riemann BL, Johnson W, Murphy T, Davies GJ. A Bilateral Comparison of the Underlying Mechanics Contributing to the Seated Single-Arm Shot-Put Functional Performance Test. J Athl Train. 2018;53(10):976-982. doi:10.4085/1062-6050-388-17

69. Chmielewski TL, Martin C, Lentz TA, et al. Normalization considerations for using the unilateral seated shot put test in rehabilitation. J Orthop Sports Phys Ther. 2014;44(7):518-524. doi:10.2519/jospt.201 $\underline{4.5004}$

70. Moore SD, Uhl TL, Kibler WB. Improvements in shoulder endurance following a baseball-specific strengthening program in high school baseball players. Sports Health. 2013;5(3):233-238. doi:10.117 $\underline{7 / 1941738113477604}$
71. Decleve P, Van Cant J, Attar T, et al. The shoulder endurance test (SET): A reliability and validity and comparison study on healthy overhead athletes and sedentary adults. Phys Ther Sport. 2021;47:201-207. d oi:10.1016/j.ptsp.2020.12.005

72. Laudner KG, Moore SD, Sipes RC, Meister K. Functional hip characteristics of baseball pitchers and position players. Am J Sports Med. 2010;38(2):383-387. doi:10.1177/0363546509347365

73. Saito M, Kenmoku T, Kameyama K, et al. Relationship Between Tightness of the Hip Joint and Elbow Pain in Adolescent Baseball Players. Orthop J Sports Med. 2014;2(5):2325967114532424. doi:10.117 7/2325967114532424

74. Sekiguchi T, Hagiwara Y, Yabe Y, et al. Restriction in the hip internal rotation of the stride leg is associated with elbow and shoulder pain in elite young baseball players. J Shoulder Elbow Surg. 2020;29(1):139-145. doi:10.1016/j.jse.2019.07.004

75. Hamano N, Shitara H, Tajika T, et al. Relationship between upper limb injuries and hip range of motion and strength in high school baseball pitchers. $J$ Orthop Surg (Hong Kong). 2021;29(1). doi:10.1177/230 $\underline{94990211003347}$

76. Burkhart SS, Morgan CD, Kibler WB. The disabled throwing shoulder: spectrum of pathology Part III: The SICK scapula, scapular dyskinesis, the kinetic chain, and rehabilitation. Arthroscopy. 2003;19(6):641-661. doi:10.1016/s0749-8063(03)0038 9-x

77. Chu SK, Jayabalan P, Kibler WB, Press J. The Kinetic Chain Revisited: New Concepts on Throwing Mechanics and Injury. PM R. 2016;8(3 Suppl):S69-77. doi:10.1016/j.pmrj.2015.11.015

78. Fleisig GS, Hsu WK, Fortenbaugh D, Cordover A, Press JM. Trunk axial rotation in baseball pitching and batting. Sports Biomech. 2013;12(4):324-333. do i:10.1080/14763141.2013.838693

79. Crossley KM, Zhang WI, Schache AG, Bryant A, Cowan SM. Performance on the single-leg squat task indicates hip abductor muscle function. Am J Sports Med. 2011;39(4):866-873. doi:10.1177/036354651039 $\underline{5456}$

80. Hatton AL, Kemp JL, Brauer SG, Clark RA, Crossley KM. Impairment of dynamic single-leg balance performance in individuals with hip chondropathy. Arthritis Care Res (Hoboken). 2014;66(5):709-716. doi:10.1002/acr.22193 
81. Wasserberger K, Barfield J, Anz A, Andrews J, Oliver G. Using the single leg squat as an assessment of stride leg knee mechanics in adolescent baseball pitchers. J Sci Med Sport. 2019;22(11):1254-1259. do i:10.1016/j.jsams.2019.06.011

82. McGovern RP, Martin RL, Christoforetti JJ, Kivlan BR. Evidence-Based Procedures for Performing the Single Leg Squat and Step-down Tests in Evaluation of Non-Arthritic Hip Pain: A Literature Review. Int J Sports Phys Ther. 2018;13(3):526-536.
83. Werner SL, Gill TJ, Murray TA, Cook TD, Hawkins RJ. Relationships between throwing mechanics and shoulder distraction in professional baseball pitchers. Am J Sports Med. 2001;29(3):354-358. doi:10.1177/036 $\underline{35465010290031701}$

84. Escamilla RF, Fleisig GS, Groeschner D, Akizuki K. Biomechanical Comparisons Among Fastball, Slider, Curveball, and Changeup Pitch Types and Between Balls and Strikes in Professional Baseball Pitchers. Am J Sports Med. 2017;45(14):3358-3367. doi:10.1177/036 $\underline{3546517730052}$ 